\title{
GESCHILPUNTEN BIJ DE VERWERKING VAN LATENTE BELASTINGVERHOUDINGEN IN DE JAARREKENING VAN ONDERNEMINGEN - $I^{1}$ )
}

door Drs. M. A. van Hoepen

\section{A. Inleiding}

Ten onrechte werden in de jaarlijkse inhoudsopgaven van dit tijdschrift de artikelen handelende over latente belastingverhoudingen steeds opgenomen onder het hoofd ,Belastingen". ${ }^{2}$ )

Ten onrechte, immers de verwerking van latente belastingverhoudingen in de jaarrekening van ondernemingen is geen belastingtechnische, of zo u wilt fiscaal-juridische zaak, neen, gegeven de fiscale winst is het een jaarrekeningprobleem. Niet alleen de rubricering van, doch ook het probleem van de latente belastingverhoudingen zelve, is een bron van misverstand en van geschilpunten. Geschilpunten die na het rapport van de z.g. „Commissie De Blaey"3) en na de discussies in dit tijdschrift ${ }^{4}$ ) vrijwel zijn blijven liggen. Door art. 23, lid 2 van de Wet op de Jaarrekening van Ondernemingen, welk artikel de vermelding van een voorziening voor passieve belastinglatenties verplicht stelt, zijn deze geschilpunten weer actueel geworden.

Ik moge onder de lezers van dit tijdschrift de problematiek bekend veronderstellen. Ik heb mij als taak gesteld in dit artikel te pogen als scheidsrechter op te treden, ten aanzien van een aantal van de m.i. grootste geschilpunten op dit terrein.

De geschilpunten die ik wil behandelen zijn:

- de wijze van vaststelling van de latente belastingverhoudingen (de statische of dynamische methode);

- de waardering van latente belastingverhoudingen;

- de saldering van actieve en passieve belastinglatenties;

- de latente belastingverplichting over de vermogensmutatie ingeval van herwaardering, alsmede de jongste wijziging die Philips te dezen aanzien heeft toegepast;

- latente belastingverhoudingen onder tariefwijziging in de belasting naar de winst;

- latente belastingaanspraken uit hoofde van het recht op voorwaartse verliescompensatie.

1) Dit artikel is voortgekomen uit de scriptie die de schrijver ten behoeve van het doctoraal examen bedrijfseconomie aan de N.E.H. te Rotterdam inleverde bij Prof. Drs. R. Burgert.

2) Zic o.m. de 38 e jaargang, 1964.

3) De "Commissie De Blaey" (genoemd naar de voorzitter) was een studiecommissie van de Com. missic Advies inzake Beroepsaangellegenheden (C.A.B.) van het toenmalige N.I.V.A., welke commissie (na $10 \frac{1}{2}$ jaar studie) cen rapport uitbracht onder de titel: „De vraagstukken welke samenhangen met de invloed van de latente bclastingverhoudingen op de jaarrekening van de naamloze vennootschap". Dit rapport is gepubliceerd in „De Accountant”, september 1962, pag. 40 e.v. In een studievergadering van het N.J.V.A., van 19 jan. 1963 werd dit rapport besproken, verslag van deze vergadering in "De Accountant", april 1963, pag. 544 e.v.

4) Zie o.m. de jaargangen 1952, 1953 en 1964.

$m a b$ blz. 38 
Ik beperk mij daarbij tot de problemen voor N.V.'s en B.V.'s; dat betekent dat de inkomstenbelasting buiten beschouwing blijft. ${ }^{5}$ )

\section{B. Statische of dynamische methode}

Met betrekking tot de vaststelling van de omvang van de latente belastingverplichtingen (resp. latente belastingaanspraken) maakt Brok onderscheid tussen de z.g. statische en dynamische methode. ${ }^{6}$ )

Wanneer men dit punt even toespitst op de latente belastingverplichtingen, kan men de statische methode omschrijven als die methode waarbij telken jare per balansdatum wordt vastgesteld welke de totale omvang van de latente belastingverplichting dient te zijn; men zou kunnen spreken van een berekening per latentie. De dynamische methode, zoals Brok die voorstaat, laat zich dan in diens woorden omschrijven als het „op basis van een voor de onderneming normatief te achten percentage (bedoeld is het geldende belastingtarief; R.v.H.), bepalen van de last, die als dotatie aan de voorzieningenrekening voor vennootschapsbelasting wordt toegevoegd. Een voorzieningenrekening waarop dus wordt afgeboekt bij het verschuldigd worden van de vennootschapsbelasting". 6 ) Men zou kunnen spreken van een berekening per periode.

De statische methode moet volgens Brok aan De Jong worden toegeschreven. ${ }^{6}$ ) Volgens De Jong moet ,... dit complexe vermogensverschil ( $\mathrm{nl}$. het verschil tussen fiscale en bedrijfseconomische winst in enig jaar; R.v.H.) ... per balansdatum geanalyseerd worden om de grootte per balansdatum van de uit het vermogensverschil voortvloeiende latentie te kunnen benaderen. Een benadering van die waarde alleen op basis van het complexe vermogensverschil ... houdt $\mathrm{nl}$. het risico in dat passieve en actieve latenties met verschillende afwikkelingstermijnen op grond waarvan verschillen in contante waarde ontstaan ..., zonder meer gecompenseerd worden". ${ }^{7}$ )

Mijns inziens gaat het hier om twee vragen, nl.:

a. Dient men de belastinglatenties te berekenen tegen contante of nominale waarde?

b. Is er aanleiding een actieve belastinglatentie lager te waarderen, omdat de mogelijkheid van virulent worden geringer moet worden geacht?

Is men van mening, dat een berekening tegen nominale waarde (vooralsnog) de voorkeur verdient (zie punt C-ad 1), dan heeft men met de verschillende afwikkelingstermijnen niets meer te maken. Is men bovendien van mening dat men met bijzondere risico's van al dan niet virulent worden niets te maken heeft, omdat het niet virulent worden van cen belastingaanspraak of het wel virulent worden van een belastingverplichting cen gebeurtenis is van

5) Terzake van de verwerking van latente belastingverhoudingen in de jaarrekening van ondernemingen die aan de inkomstenbelasting zijn onderworpen, rijzen problemen t.a.v. a) de vraag of de belasting hier een bedrijfslast dan wel een gedwongen particuliere inkomensbesteding vormt, b) de verwerking van veelvuldige tariefswijzigingen i.v.m. de progressie in het tarief, c) de verwerking van de horizontale verliescompensatie.

6) A. L. Brok: „Latenties terzake van de vennootschapsbelasting"; M.A.B. 1964, pag. $231 / 232$.

7) J. de Jong; "Latenties terzake van de vennootschapsbelasting”; M.A.B. 1964, pag. 43. 
het jaar waarin dat niet of wel virulent worden zich voordoet (er is met andere woorden sprake van een, al dan niet bijzondere, last van dat jaar - zie punt G), dan is er in wezen geen verschil meer tussen de statische en de dynamische methode, beide leiden tot dezelfde latentiebedragen.

Dit betekent echter geenszins, dat men indifferent tussen beide methoden zou kunnen zijn. De dynamische methode, waarbij de belasting over het verschil tussen fiscale en bedrijfseconomische winst in enig jaar wordt toegevoegd, resp. onttrokken aan de reeds op de balans opgevoerde belastinglatenties, is onvoldoende om drie redenen:

a. Allereerst zal men na moeten gaan, in hoeverre het in enig jaar geconstateerde verschil tussen fiscale en bedrijfseconomische winst veroorzaakt wordt door winstverschuivingen, in welk geval latente belastingverhoudingen ontstaan en in hoeverre er geen sprake is van winstverschuiving, maar van een definitieve verzwaring of verlichting van de belastingdruk op de bedrijfseconomische winst, doordat de fiscus niet in latere jaren door tegengestelde "correcties" op het verschil tussen fiscale en bedrijfseconomische winst ,terugkomt".

$b$. Het verschil tussen fiscale en bedrijfseconomische winst, voorzover dat door winstverschuiving is veroorzaakt, zal moeten worden gesplitst in aanspraken op en verplichtingen aan de fiscus. Niet alleen wanneer men de latente belastingaanspraken en -verplichtingen afzonderlijk, d.w.z. niet gesaldeerd op de balans wil opnemen (zie punt D), maar evenzeer wanneer men tot saldering van aanspraken en verplichtingen wil overgaan, doch het reëel acht de aanspraken lager te waarderen dan de verplichtingen, omdat men meent rekening te moeten houden met het feit dat het risico van niet virulent worden van de aanspraken groter is dan het risico van wel virulent worden van de verplichtingen (zie opvattingen onder punt C-ad 2).

c. Tenslotte zal men, zowel onder toepassing van de contante waarde, als onder toepassing van de nominale waarde methode, in het oog moeten houden of de latenties, met name de actieve latenties, wel virulent worden. Immers bij niet virulent worden van een latente belastingaanspraak, zal men wanneer verliescompensatie niet meer mogelijk blijkt een (bijzondere) last, of bij niet virulent worden van een latente belastingverplichting een (bijzondere) bate, moeten opvoeren op de resultatenrekening of overboeken naar een reserverekening. De verwachte virulentietijdstippen kan men alleen te weten komen door per ontstaansoorzaak van de latentie(s) de latere fiscale ,,correcties" op te sporen. ${ }^{8}$ )

De enige methode om aan de drie voorgaande punten te voldoen is om het verschil dat zich in een bepaald jaar voordoet tussen fiscale en bedrijfseconomische winst (het periodeverschil) te analyseren naar ontstaansoorzaken (de statische methode). Door alleen te zien naar het periode-verschil (de dyna-

\footnotetext{
B) De door A.P.B. opinion nr. 11 gemaakte onderscheiding tussen "current" en ,non-current" latente belastingverhoudingen, welke onderscheiding door $\mathrm{H}$. L. Brink in het laatste juninummer van dit tijdschrift werd gelaakt (M.A.B. 1972, pag. 246), is niet alleen van belang om het virulent worden der belastinglatenties in het oog te houden, doch is evenzeer nuttig voor de lezer der jaarrekening om inzicht te krijgen in de mogelijke liquiditeitsontwikkeling van de onderneming.
} 
mische methode) kan men niet bepalen of, en in hoeverre, er sprake is van winstverschuiving, noch in hoeverre het verschil is opgebouwd uit aanspraken en verplichtingen en evenmin kan men in het oog houden of de afwikkeling van de latenties het normaal geachte verloop heeft.

\section{De waardering van latente belastingverhoudingen}

Het probleem van de waardering der in de balans voor actieve en passieve latenties op te voeren posten, valt $m$.i. in tweeën uiteen:

1. de vraag of men de latente belastingverhoudingen moet waarderen tegen contante of tegen nominale waarde;

2. de vraag of er aanleiding bestaat bij actieve latenties over te gaan tot een lagere waardering in verband met het bijzondere risico, dat bij virulent worden van deze aanspraak, een daadwerkelijke verrekening wel eens onmogelijk kan zijn, doordat onvoldoende winst is behaald.

\section{Ad-1}

De vraag naar het al of niet waarderen tegen contante waarde hield en houdt de meningen sterk verdeeld. Ook de „commissie De Blaey” onthield zich (waarschijnlijk voorzichtigheidshalve) van een pertinent oordeel, hoewel een lichte neiging naar waardering tegen nominale waarde te bespeuren valt. ${ }^{9}$ ) Het grootste struikelblok vormt hier de vraag aan welk jaar het rentevoordeel dat wordt genoten in geval van het aanhouden van latente belastingverplichtingen" moet worden toegerekend. De latente belastingverplichting immers vormt een renteloze ,schuld" aan de fiscus. De aanhangers van de nominale waarde methode verdedigen hun opvatting door te wijzen op het causaliteits-beginsel, immers bij de nominale waarde methode wordt het rentevoordeel over de "renteloze schuld" toegerekend aan de jaren waarin het ,uitstel van betaling" wordt genoten. De aanhangers van de contante waarde methode bepleiten hun standpunt op grond van een juiste presentatie van de grootte en de samenstelling van het vermogen.

Het is enigszins verwonderlijk, dat de discussie over de waardering op nominale of contante waarde zich juist t.a.v. de belastinglatenties heeft voorgedaan. Het is namelijk een vraagstuk, dat zich tot de hele jaarrekeningpıblematiek uitstrekt. Theoretisch-economisch geredeneerd lijkt mij slechts de contante waarde methode verdedigbaar. Bij het werken met de contante waarde van toekomstige ontvangsten en toekomstige uitgaven stelt de contante waarde van het overschot van toekomstige ontvangsten boven toekomstige uitgaven het „capital" voor, als zijnde ,, a stock of wealth existing at an instant of time"10 ${ }^{10}$, een voor (bedrijfs)economisten m.i. als enig denkbaar universeel vermogensbegrip. Toepassing van de contante waarde methode leidt op deze wijze tot hantering van het z.g. ,economisch winstbegrip" 1 ). De wens tot toepassing van de contante waarde berekening bij de

9) „De Accountant", 69e jaargang, pag. 50.

$10)$ Irving Fisher: "The nature of capital and income", 1906.

11) Het valt m.i. buiten het kader van een artikel als dit, om her wel en wee van het economisch winstbegrip breder uit te meten. 
latente belastingverhoudingen, kan ik dan ook niet anders zien dan als een, vaak wellicht gedeeltelijk onbewuste, wens tot toepassing van het economisch winstbegrip. Ik kan me nauwelijks voorstellen, dat men, met name de latente belastingverplichtingen, contant zou willen maken omdat over deze toekomstige schuld aan de fiscus geen rente zou moeten worden vergoed; want waarom heeft men zich dan niet of nauwelijks druk gemaakt over de vraag of men ook opgenomen renteloze of laagrentende leningen niet tegen hun contante waarde op de balans dient op te nemen?

Tegen een dusdanige partiële toepassing van het economisch winstbegrip, d.w.z. voor de latente belastingverhoudingen alleen, moet, dacht ik, ernstig gewaarschuwd worden, omdat:

a. Indien men van mening is dat een voorstelling van het vermogen op basis van de nominale waarde onjuist is, men deze voorstelling in wezen niet nog onjuister althans verwarrender moet gaan maken door bepaalde bestanddelen van dat vermogen opeens op contante waarde te gaan waarderen.

$b$. De toepassing van het economisch winstbegrip m.i. nog onvoldoende doordacht is, om tot een praktische toepassing daarvan over te gaan (gesteld al dat dit mogelijk zou zijn), voorlopig zullen we het nog steeds moeten stellen met het „,boekhoudkundig winstbegrip" (,,accounting concept of profit"), dat om met een monetaire term te spreken, onder uitsluiting van het economische winstbegrip, de „Massengewohnheit der Annahme" bezit, of, zoals u wilt, voldoet aan "de normen welke in het maatschappelijk verkeer als aanvaardbaar worden beschouwd".

Zulks geldt eens te meer voor de tussenoplossing welke door Burggraaff is gesuggereerd, welke een waardering van belastinglatenties (i.c. belastingverplichtingen) op contante waarde inhoudt, onder toerekening van het ,rentevoordeel" aan de jaren waarin ,uitstel van betaling" wordt genoten, door passivering van dit rentevoordeel als vooruit ontvangen inkomsten op de balans. ${ }^{2}$ ) Men zal er evenwel rekening mee moeten houden, dat over dit rentevoordeel door de fiscus weer belasting wordt geheven. Voor dit probleem geeft De Jong de oplossing aan:

het contant maken dient te geschieden tegen:

$\left.[(1 \% \text { - belastingperunage }) \times \text { rentevoet voor langlopende leningen }]^{13}\right)$

Het is wellicht niet ondienstig deze zienswijze met een voorbeeld te verduidelijken:

Voorbeeld:

Aanschaffingsprijs machine: $f 12.000,-$. Levensduur (fiscaal en bedrijfseconomisch): 8 jaar. Vervroegde afschrijving: $1 / 3$ maximaal vervroegd. Belastingtarief: $50 \%$. Rentevoet voor langlopende leningen: $10 \%$. Winst vòor afschrijving en belasting (fiscaal en bedrijfseconomisch): $f$ 8.000,- per jaar.

12) J. A. Burggraaff: „Latenties terzake van de vennootschapsbelasting”; M.A.B. 1964, pag. 248.

13) J. de Jong, t.a.p. Het is m.i. echter nog wel de vraag of een juiste toepassing van het "opportunity costs" beginsel niet meebrengt dat men met de z.g. "firms costs of capital" dient te werken. 


\begin{tabular}{|c|c|c|c|c|c|c|c|}
\hline d & 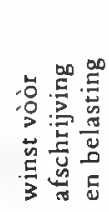 & 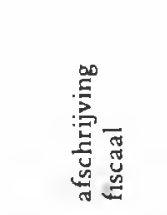 & 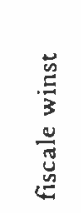 & 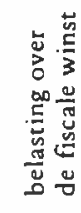 & 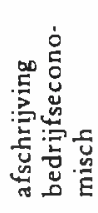 & 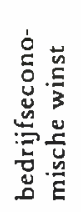 & 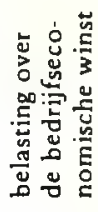 \\
\hline 1 & 8.000 & $4.000+1.000$ & 3.000 & 1.500 & 1.500 & 6.500 & 3.250 \\
\hline 2 & 8.000 & 1.000 & 7.000 & 3.500 & 1.500 & 6.500 & 3.250 \\
\hline 3 & 8.000 & 1.000 & 7.000 & 3.500 & 1.500 & 6.500 & 3.250 \\
\hline • & $\bullet$ & $\bullet$ & • & : & $\bullet$ & $\bullet$ & $\bullet$ \\
\hline 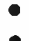 & $\bullet$ & $\because$ & 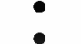 & $\bullet$ & : & : & - \\
\hline 8 & 8.000 & 1.000 & 7.000 & 3.500 & 1.500 & 6.500 & 3.250 \\
\hline
\end{tabular}

Jaarlijks wordt nu van de belastinglatentie $f 250,-$ virulent (zijnde het belastingtarief toegepast op het jaarlijks afschrijvingsverschil) en dat gedurende 7 jaar $(2 \mathrm{e} \mathrm{t} / \mathrm{m} 8 \mathrm{e}$ jaar $)$. Het toe te passen rentepercentage is $(1-0,50) \times 10 \%=5 \%$. De contante waarde van de passieve latentie aan het eind van het eerste jaar is dan $250 \times$ a $715=f 1.446,59$.

De te verrichten boekingen zijn nu de volgende:

1e jaar:- Resultatenrekening (belasting

over bedrijfseconomische winst)

aan Te betalen belasting (belasting

over fiscale winst)

aan Nog niet opeisbare belasting-

schuld $\left.{ }^{4}\right)(250+$ a 715$)$

aan Vooruitontvangen intrest (verschil)

$3.250,-$

$1.500,-$

$1.446,59$

303,41

2e jaar:- Vooruitontvangen intrest ( $50 \%$ van $10 \%$ van $1.446,59$ )

aan Nog niet opeisbare belastingschuld ${ }^{14}$ )

- Resultatenrekening (belasting over

bedrijfseconomische winst)

Nog niet opeisbare belastingschuld

aan Te betalen belasting (belasting over fiscale winst)

Rentekosten

[o.m. 10\% van $(1.446,59+303,41)$ ]

aan Ingecalculeerde rente

$3.250,-$

$250,-$

$3.500,-$

$175,-$

Duidelijk blijkt nu dat het rentevoordeel over de "renteloze schuld" aan de fiscus, ook bij toepassing van de contante waarde methode niet behoeft te worden toegerekend aan het jaar waarin de verplichting ontstaat. Evenwel levert de sommering van de contante waarde van de latente belastingver-

14) Bedoeld is de latente belastinguerplichting; de benaming ,nog niet opeisbare belastingschuld" acht ik voor een presentatie op de balans (en voor de aanduiding van de betreffende grootboekrekening) echter duidelijker en taalkundig gezien juister.

$m a b$ blz. 43 
plichtingen en de gepassiveerde intrest voor elk jaar precies de nominale waarde van de latente belastingverplichting op. Hieruit blijkt m.i. duidelijk dat het partieel werken met de contante waarde geen soelaas kan bieden voor de ontkoming aan de uit het boekhoudkundig winstbegrip voortvloeiende „onjuiste" voorstelling van de grootte en de samenstelling van het vermogen. ${ }^{15}$ )

Zolang we het boekhoudkundig winstbegrip (moeten) blijven hanteren, kunnen we, ook voor de latente belastingverhoudingen, slechts waardering op nominale waarde toepassen, zulks brengt het consistentiebeginsel met zich mee.

\section{Ad-2}

De tweede vraag bij de waardering van latente belastingverhoudingen was, of er aanleiding is bij actieve latenties over te gaan tot een lagere waardering, in verband met het bijzondere risico dat bij virulent worden van deze aanspraak een daadwerkelijke verrekening wel eens onmogelijk kan zijn, door onvoldoende winst in het jaar van virulent worden. Door vrijwel alle mij bekende schrijvers over dit onderwerp wordt deze vraag, zij het in verschillende schakering van overtuiging bevestigend beantwoord. Deze verschillende schakering van overtuiging heeft geleid tot verschillende antwoorden, variërend van op nihil waarderen van alle actieve latenties (o.m. De Koning ${ }^{16}$ ), via het op nihil waarderen van per saldo actieve latenties (dus na saldering met de passieve latentie - o.m. De Jong ${ }^{1}$ ), tot het niet op volle (nominale of contante) waarde opnemen van actieve latenties (o.m. de "Commissie De Blaey"18). De argumentatie voor deze opvattingen valt in de woorden van de „Commissie De Blaey" als volgt te omschrijven:

„Naarmate de onzekerheid zou groeien ten aanzien van de winstcapaciteit van de onderneming in de toekomst, naar diezelfde mate neemt de waarde af van de objecten, die deze uiteindelijk aan de winstcapaciteit ontlenen". ${ }^{18}$ ) Terecht merkt Brok evenwel op, dat het niet tot verrekening komen van een actieve latentie zich alleen zal kunnen voordoen, ,, wanneer in het jaar van geheel of gedeeltelijke afloop van een z.g. latente claim niet tevens tot een gelijk bedrag een latente verplichting tot afwikkeling komt, terwijl dan bovendien in totaal nog sprake moet zijn van een fiscaal verlies dat binnen de gestelde termijn niet tot verrekening gebracht kan worden". ${ }^{19}$ ) Brok verzuimt evenwel hieruit de conclusie te trekken, dat het in enig jaar voldoen aan de door hem geschetste voorwaarden, dan toch wel duidelijk een bijzondere gebeurtenis is die op dàt betreffende jaar betrekking heeft. Immers wanneer een actieve latentie, onder de door Brok geschetste voorwaarden, niet tot verrekening kan komen, kan men moeilijk beweren, dat de oorzaak

15) Let wel dat bijv. het op contante waarde waarderen van pensioenverplichtingen (goed koopmansgebruik - boekhoudkundig winstbegrip!) niet geschiedt (althans niet in de eerste plaats) om te komen tot een juiste voorstelling van de omvang van het vermogen, maar t.b.v. een juiste toerekening van baten en lasten aan de opeenvolgende jaren.

16) „De Accountant”, 69e jaargang, pag. 528 .

17 ) J. de Jong, t.a.p. pag. 45 en 54.

18 ) „De Accountant", 69e jaargang, pag. 47

19 ) A. L. Brok, t.a.p. pag. 233/234. 
daarvan ligt in het feit dat belasting ,,vooruit betaald" is.

De oorzaak van onverrekend blijven ligt in de afwezigheid, of het onvoldoende zijn van de winst in het jaar waarin deze actieve latentie virulent zou worden. (In dit geval ontstaat volgens mij overigens weer een actieve latentie, voor hetzelfde bedrag als onverrekend bleef, maar nu in verband met het recht op toekomstige voorwaartse verliescompensatie, even afgezien van de z.g. , carry-back" - zie punt G).

$\mathrm{Nu}$ kan men het niet opvoeren, of lager waarderen van een (eventueel per saldo) actieve latentie wel willen verdedigen met het voorzichtigheidsargument, doch hier is m.i. sprake van een misplaatste voorzichtigheid. Dit is dezelfde voorzichtigheid als op grond waarvan jarenlang het opvoeren van stille en geheime reserves als goed koopmansgebruik is beschouwd. Voorzichtigheid binnen de grenzen der waarachtigheid houdt toch niet in dat men zonder meer vorderingen ,,beneden pari” kan waarderen? Bovendien zullen degenen die de actieve latenties in het geheel niet, of slechts ,beneden pari” op de balans willen opnemen, zich goed dienen te realiseren, dat men in strijd komt met de doelstelling van de belastinglatenties, zijnde het op de resultatenrekening opvoeren van een bedrag aan belasting dat met het (bedrijfseconomisch) winstbedrag qua tarief in een duidelijk verband staat. Immers wanneer de fiscale winst (tijdelijk) groter is dan de bedrijfseconomische, en men wil op de resultatenrekening slechts de (lagere) belasting over de bedrijfseconomische winst opvoeren, dan zit er niets anders op, dan het verschil in belasting over de bedrijfseconomische en de fiscale winst voor het volle bedrag te activeren in de balans, resp. voor het volle bedrag te salderen met de reeds aanwezige passieve latenties.

Voor een lagere waardering van actieve latenties kan wellicht slechts aanleiding zijn, wanneer een onderneming voorziet dat zij voorlopig geen of onvoldoende (fiscale) winst zal behalen om de virulent wordende actieve latenties op ,af te boeken" (althans niet binnen de daarvoor gestelde verliescompensatietermijn), terwijl deze actieve latenties ook niet, of niet ten volle en op dezelfde tijdstippen met passieve latenties gecompenseerd kunnen worden. Deze situatie is evenwel m.i. een zodanig uitzonderlijke, dat de gerechtvaardigdheid van toepassing van de ,going-concern" gedachte bij de opstelling van de jaarrekening nauwelijks meer aanwezig lijkt, er zal alle aanleiding zijn ook andere activa dan de actieve latenties niet meer op hun ,goingconcern" waarde te waarderen, maar veelal op hun liquidatiewaarde. Men is dan evenwel op een algemeen waarderingsprobleem terecht gekomen. Zeker is er geen aanleiding om als algemene regel actieve (of per saldo actieve) latenties ,beneden pari” of in het geheel niet te waarderen.

\section{De saldering van actieve en passieve belastinglatenties}

De saldering van actieve en passieve latenties houdt ten nauwste verband met de hiervoor vermelde waardering van de actieve belastinglatenties.

Inherent aan het op nihil of ,beneden pari" waarderen van per saldo actieve latenties is immers de saldering van deze actieve met de passieve 
latenties. ${ }^{20}$ ) De Koning geeft een drietal motieven voor deze saldering: a. ,Het saldo latente belastingschuld of latente belastingaanspraak (heeft) betrekking... op het saldoverschil tussen bedrijfseconomische en fiscale winst in het verleden, voorzover dit in de toekomst door een tegengesteld verschil wordt opgeheven",

$b$. „De afloop van de latentie (loopt) parallel ... met het ontstaan van deze toekomstige verschillen",

c. „Bestaat er per saldo een verplichting dan zijn de winstverwachtingen voor de waardering van een eventuecl hierin als aftrekpost begrepen aanspraak niet relevant. Blijft de winst uit en daardoor de mogelijkheid tot realisering van de aanspraak, dan valt een gelijk bedrag van verplichtingen vrij". ${ }^{21}$ )

De in dit derde motief tot uitdrukking gebrachte gedachte, als zou men actieve en passieve latenties volledig kunnen salderen en alleen de per saldo actieve latentics (blijkbaar) ,beneden pari" of op nihil kunnen waarderen, is niet alleen in strijd (zoals ik onder punt C-ad2 aangaf) met de doelstelling van het opvocren van belastinglatenties, maar kan bovendien leiden tot een sterk schoksgewijze verloop van de op de resultatenrekening voor winst ná belasting op te voeren bedragen, dit afhankelijk van de toevallig bestaande omvang van de passieve belastinglatenties in enig jaar.

Een en ander kan overigens niet leiden tot de conclusie dat de actieve latenties in hun geheel (dus niet alleen per saldo) ,beneden pari" zouden moeten worden gewaardeerd. Deze opvatting heb ik onder het voorgaande punt (C-ad 2) mede als onjuist gekenschetst.

Evenmin kan men echter op grond van de twce resterende argumenten van De Koning ( $a$ en b) concluderen dat men de ,volle waarde" van de actieve latenties kan salderen met de ,volle waarde" van de passieve latenties. Weliswaar is de gedachte om in één bedrag op de balans de ,verhouding" tot de fiscus tot uitdrukking te brengen verleidelijk, doch deze gaat voorbij aan het feit dat acticve latenties van een ander karakter zijn dan passieve latenties. Ik wil zeker niet zover gaan als de „Commissie De Blacy”, die de wat verwonderlijke opvatting huldigt dat de passieve latenties een voorziening en actieve latentics een soort transitorische post vormen ${ }^{22}$ ), maar vooruitbetalen (in dit geval van belasting) is iets anders dan achteraf betalen. Allcen al omdat actieve latenties op andere tijdstippen virulent kunnen worden, en op andere „,oorzaken" betrckking hebben, kan men ze zcker onder de nominale waarde methode niet salderen. Tenslotte kan men alle debet balansposten ook tegen de creditposten wegstrepen. Het tegen elkaar laten vervallen van schulden en vorderingen (en ik begrijp daar nu ook maar de toekomstige schulden $\mathrm{cn}$ toekomstige vorderingen onder, wat latente belastingverhoudingen in wezen zijn) is m.i. binnen de jaarrekening alleen dān geoorloofd, als:

${ }^{20}$ ) Op het feit dat voor de volle acticve latenties het gevaar van niet honorabel zijn van deze vorderingen door onvoldoende winst bestaat, en niet allecn voor de per saldo actieve latenties wordt alleen door Brok en De Jong gewezen.

21) De bewoordingen zijn van W. N. de Blacy in zijn antwoord aan R. de Koning, zie ,De Accoustant",69e jaargang, pag. 539

22) „De Accountant", 69 caargang, pag. 49

ma b blz. 46 
a. het betreft een schuld aan, en vordering op eenzelfde persoon of lichaam, en

$b$. er sprake is van een rekening-courant verhouding (waarbij door renteberekening de verschillen tussen vervaltermijnen van vorderingen en schulden „,automatisch" worden rechtgetrokken).

Van een dergelijke ,rekening-courant verhouding" tussen fiscus en onderneming is zeker (nog) geen sprake. Bovendien biedt men de lezer van de jaarrekening een duidelijker inzicht in de ,lange termijnverhouding" tot de fiscus, indien men afzonderlijk actieve en passieve latenties op de balans opneemt, dan wannecr men alleen het ,saldo" opneemt.

In dit laatste geval heeft de lezer der jaarrekening nog geen enkel idee omtrent de omvang van de bedragen die in de "lange termijnverhouding" tot de fiscus een rol spelen. 